\title{
DO DIREITO HUMANO FUNDAMENTAL À SAÚDE: O BINÔMIO VIDA E MORTE ATRAVÉS DE UMA REFLEXÃO SOCIOJURÍDICA SOBRE O FENÔMENO DO SUICÍDIO
}

\author{
Janaína Machado Sturza ${ }^{1}$ \\ Rodrigo Tonel ${ }^{2}$
}

\section{RESUMO}

O fenômeno do suicídio, como ato intencional de matar a si mesmo, manifesta-se na contemporaneidade como pauta dos debates acerca da promoção e proteção do direito humano fundamental à saúde. Este artigo tem por objetivo estimular a reflexão sociojurídica sobre este fenômeno - enquanto risco à preservação da vida humana, retratado através do binômio vida e morte. Através de um estudo bibliográfico, tendo como método de abordagem o hipotético dedutivo, verificou-se como essencial e urgente políticas públicas que comunguem iniciativas estratégicas nos campos da saúde pública, biodireito e direitos humanos, visando resguardar a vida e a própria espécie humana.

Palavras-Chave: Direito humano e fundamental à saúde; direito à vida; morte; políticas públicas; suicídio.

\section{THE FUNDAMENTAL HUMAN RIGHT TO HEALTH: THE BINOMIAL LIFE AND DEATH THROUGH A SOCIOJURIDICAL REFLECTION ON THE PHENOMENON OF SUICIDE}

\begin{abstract}
The phenomenon of suicide, an intentional act of killing oneself, has manifested itself in contemporaneity as the agenda for debates about the promotion and protection of the fundamental human right to health. This article aims to encourage the socio-juridical perception on this phenomenon - while a risk to the preservation of human life, represented through the binomial life and death. Through a bibliographical study, using the hypothetical deductive method, it's been verified as essential, initiatives that communicate strategic public policies in the fields of public health, biolaw and human rights, aiming to protect life and the human species itself.
\end{abstract}

Keywords: Human and fundamental right to health; Right to life; death; public policy; suicide.

\footnotetext{
${ }^{1}$ Pós doutora em Direito pelo Programa de Pós Graduação em Direito da Universidade do Vale do Rio dos Sinos - UNISINOS. Doutora em Direito pela Escola Internacional de Doutorado em Direito e Economia Tullio Ascarelli, da Universidade de Roma Tre/Itália. Mestre em Direito pela Universidade de Santa Cruz do Sul UNISC. Especialista em Demandas Sociais e Políticas Públicas também pela UNISC. Graduada em Direito pela UNISC. Professora na Universidade Regional do Noroeste do Estado do Rio Grande do Sul - UNIJUÍ, lecionando na graduação em Direito e no Programa de Pós Graduação em Direito - Mestrado e Doutorado. Integrante do grupo de pesquisa Biopolítica e direitos humanos (certificado pelo CNPq). Email: janasturza@hotmail.com

${ }^{2}$ Mestrando no Programa de Pós-Graduação em Direitos Humanos - Mestrado e Doutorado, da Universidade Regional do Noroeste do Estado do Rio Grande do Sul - UNIJUI, Bolsista da Coordenação de Aperfeiçoamento de Pessoal de Nível Superior - CAPES. Bacharel em Direito pela UNIJUÍ. Email: tonelr@ yahoo.com
} 


\section{INTRODUÇÃO}

Ao longo da história da humanidade, o fenômeno do suicídio sempre esteve presente nas mais diversas civilizações. Em algumas, este fenômeno se mostrou mais intenso, e em outras mais tênue. Portanto, é fato que a humanidade convive, de longa data, com o binômio vida e morte - nas suas mais diversas acepções, para além do fenômeno do suicídio.

Neste contexto, o presente artigo propõe-se a fazer uma abordagem sociojurídica a respeito do fenômeno do suicídio e o crescente aumento de sua ocorrência na sociedade contemporânea, discutindo-se, igualmente, a importância de políticas públicas voltadas a sua prevenção e decorrente proteção ao direito humano fundamental à saúde e consequentemente à vida.

$\mathrm{Na}$ sociedade contemporânea, o fenômeno do suicídio apresenta-se como um problema de saúde pública, destacando-se como pauta dos debates sobre a promoção e proteção do direito humano fundamental à saúde, no sentido de identificar as principais causas que levam as pessoas a abreviação de suas existências. De igual modo, os debates seguem na tentativa de fomentar espaços de análise e reflexão acerca dos temas que envolvem o binômio vida e morte - e por consequência suicídio, tais como a autonomia e liberdade do ser humano em dispor ou não pelo seu corpo físico, ou seja, as discussões relativas ao direito à vida e à morte e a liberdade de escolha e/ou opção voluntária do indivíduo pela morte, frente a intervenção do Estado na vida do indivíduo, mediante o dever estatal de proteger a vida.

Nesse sentido, o tema ora proposto se justifica pela sua relevância nos campos da saúde pública, do biodireito e dos direitos humanos, além da contribuição sociojurídica no que concerne aos fundamentos e marcos teóricos e normativos - afinal, o suicídio deve ser um tema de domínio abrangente, especialmente diante do preocupante aumento das taxas de morte provindas deste fenômeno. O momento é extremamente oportuno e necessário para debater o tema, eis que a vida e a saúde são bens comuns da humanidade.

Desta forma, através do emprego do método hipotético-dedutivo - que parte de uma premissa maior a fim de estabelecer uma conclusão específica acerca do tema proposto - e da técnica de pesquisa bibliográfica, verificou-se como essencial e urgente iniciativas de formulação e implementação de políticas públicas de prevenção ao suicídio, à partir da projeção de um novo horizonte de possibilidades no que diz respeito às estratégias nos 
campos da saúde pública, biodireito e direitos humanos, de tal modo que exista uma garantia da promoção efetiva do direito humano fundamental à saúde enquanto um valor universal, voltado para a valorização da vida como bem maior.

\section{Entre a moralidade e a imoralidade, entre a loucura, os devaneios e o pecado: a (ir)racionalidade do suicídio}

Por uma razão cultural, o suicídio é visto como imoral, tabu, pecado, ato de reprovação pela maioria das pessoas, o que, consequentemente, faz com que este fenômeno não seja discutido com clareza e com calma e que, muitas vezes, é dispensado de discussões, simplesmente porque, para o senso comum, pessoas que se suicidam ou tentam se suicidar são compreendidas como loucas acometidas por doenças mentais e que devem ser internadas e tratadas por psiquiatras. Mesmo assim, o próprio fato de estar contemplando suicídio é evidência de que o indivíduo está louco.

Conforme Epicurus (n.d., n.p., tradução nossa), “[...] a morte, portanto, o mais terrível dos males, não é nada para nós, visto que, quando estamos, a morte não vem e, quando a morte chega, não estamos. Não é nada, então, nem para os vivos nem para os mortos, pois os vivos não são e os mortos não existem mais."

Desta forma, algo pode ser ruim para um ser humano somente quando este existe e/ou está vivo, porque quando se está morto se supõe que não existe e/ou deixou de existir e, portanto, a morte não pode ser algo ruim.

Importante frisar que ninguém sabe ao certo se a vida continua após a morte ou se a morte é literalmente o fim. A título de ilustração poderíamos citar religiões, filosofias e teorias científicas que sustentam a continuação da vida após a morte, seja pela existência da alma, conforme opinam as correntes defensoras do dualism - dualismo (CRAIG, 1979), ou pela reincorporação de energia liberada por nossos cadáveres quando mortos, conforme preleciona a física quântica - ainda pouco estudada (LANZA; BERMAN, 2010). Outras correntes, como os que apoiam as teorias evolucionistas, afirmam que a morte é o fim e que, logicamente, não há vislumbre de continuação de vida após a morte, visto ser esta um processo natural de evolução do ser humano (DARWIN, 2014). Contudo, o que se sabe é que o corpo humano físico irá passar por um processo natural de decomposição. Discutir a vida 
pós morte é uma questão para outras oportunidades, visto que o escopo que aqui tratamos refere-se à racionalidade pela opção da morte quando vivos num corpo físico.

De acordo com Kagan (2012, p. 324, grifo do autor, tradução nossa), “[...] não é que, estando morto, ele estaria em uma condição que é boa, ou uma condição que é melhor do que estar vivo. É simplesmente que, ele estando morto, evitaria esta condição miserável que é claramente uma condição ruim."

Para a Valuable Container Theory - Teoria do Container Valioso -, o simples fato de estarmos vivos significa que a vida é valiosa, ou seja, não importa o quão ruim e miserável seja a vida, porque mesmo assim estar vivo (e, portanto, existir) é melhor do que estar morto (não existência). Agora, para a Neutral Container Theory - Teoria do Container Neutro -, o valor da vida é dado por seus conteúdos prazerosos e dolorosos (KAGAN, 2012).

Para alguns, a vida é tão ruim que seria melhor morrer. A vida é tão cheia de sofrimento e miséria que, quaisquer que sejam os prazeres, estes são sempre superados por aqueles.

Existem teorias a respeito do que é a vida. Se optarmos pela aceitação do que prega o hedonismo, onde a qualidade de vida é a baseada na adição de todo o prazer e subtração de toda a dor. Se o resultado deste cálculo por positivo, isto é, se o prazer se sobrepor a dor, então, a vida vale a pena ser vivida. Porém, se o resultado for negativo, evidenciando-se mais dor do que prazer, então, a vida acaba não valendo a pena.

Situações comuns como o término de um relacionamento, a perda do emprego, morte de um ente querido, entre outras. Isto é, frustações que acontecem durante a vida, onde as pessoas não pensam claramente e acabam optando pelo suicídio. Todavia, tais situações normalmente acometem as pessoas por um período, e que, com o passar do tempo essa agonia passa, e contemplar o suicídio não algo racional.

No entanto, se tomarmos por exemplo a situação de alguém que está diagnosticado com câncer degenerativo e que como sintomas tem-se dores insuportáveis e esta condição tende a permanecer pelo resto da vida, sem perspectiva de melhora, então, talvez o suicídio seria uma opção racional. O detalhe é que nunca saberemos com certeza absoluta como nosso quadro de saúde estará no futuro.

Se tivéssemos uma bola de cristal que nos permitisse ver o futuro, ou uma máquina do tempo como a da trilogia de filmes Back to the Future - De Volta para o Futuro -, que nos possibilitasse realizar viagens no tempo com a finalidade de averiguar nosso quadro de saúde 
no futuro, para termos certeza se estaremos melhores ou piores e, então, retornar ao presente para então decidirmos pela abreviação deliberada de nossas existências diante da certeza de nossa condição de saúde no futuro, isto é, se vale a pena ou não continuarmos vivendo, então, o suicídio seria uma opção racional. Contudo, como não dispomos de uma máquina do tempo, tampouco, uma bola de cristal, permanecemos na incerteza de melhora ou piora.

O que dispomos são prognósticos médicos baseados em casos semelhantes aos nossos e tecnologias que nos permitem avaliar as possibilidades de melhora ou piora. Tomamos o exemplo de um paciente que tem $99,9 \%$ chances de só piorar no futuro e $0,01 \%$ chance de recuperação. Abrem-se, então, dois caminhos a serem tomados, um rumo escolha pelo suicídio e outro rumo a continuação da existência na esperança (mesmo que mínima) de recuperação. Porém, por mais que pareça improvável a recuperação e mesmo que as chances sejam as mais mínimas possíveis, ainda existe a possiblidade de melhora. E, mesmo diante da possibilidade de piorar cada vez mais, esta possibilidade pode ainda restar frustrada. Percebemos neste exemplo, que tudo é muito relativo e, que, somente se continuarmos vivos é que saberemos se nosso quadro irá piorar ou melhorar, ao passo que, se optarmos pela morte, nunca saberemos de fato o que aconteceria (KAGAN, 2012).

Na posição de Shelly Kagan (2012), em alguns contextos muito particulares quando não se tem vislumbre de melhora no decorrer da vida - e, após uma profunda reflexão realizada pelo indivíduo em sã consciência, sim, pode ser racional cometer suicídio. Porém, isso não significa que pode ser algo moralmente aceito pela sociedade, por exemplo.

Por um outro viés, há aqueles que defendem a escolha e/ou opção pela morte, ou seja, a morte como um direito advindo da liberdade estatal concedida ao cidadão (SZASZ, 1999). E, nesse sentido, é importante destacar que a vida humana, especificamente no que concerne a existência física, tem limites determinados e claros.

\section{O limite para a existência humana: a morte e o suicídio}

Até onde sabemos, nossa existência é limitada, ou seja, não podemos viver eternamente, uma vez que nosso corpo físico está condicionado a viver temporariamente devido a fatores biológicos. Morrer é um processo natural da vida, assim como nascer é um acontecimento natural para iniciar o ciclo de vida de um ser vivo, enquanto um nascimento é muitas vezes celebrado com felicidade, a morte é vista com tristeza e geralmente evitada em 
todos os esforços. Todo ser vivo está destinado a morrer no final de sua vida. Assim, todos nós sabemos que um dia morreremos. É verdade que podemos adiar nossas mortes através das tecnologias que temos, através de medicamentos e tratamentos, mas não podemos evitar a morte. Nós simplesmente não podemos controlar esse fato (KÜBLER-ROSS, 1986). De acordo com Carnell (2007, pp. 23-24, tradução nossa),

\begin{abstract}
A incongruência entre o desejo do homem pela vida e a realidade da morte física é o problema mais enlouquecedor de todos. Embora ele veja a caligrafia na parede, o homem ainda se recusa a pensar que a morte é o seu destino final, que ele perecerá como o peixe e a ave, e que o seu lugar não será mais lembrado. O homem quer viver para sempre; o desejo está escrito profundamente em sua natureza.
\end{abstract}

No mesmo contexto, Thomason (2002, p. 270, tradução nossa) sustenta que,

A crença na sobrevivência após a morte não é apenas universal, mas muito antiga. Os egípcios acreditavam; na Grécia, foi adotada pelos órficos, de quem Platão a recebeu; os hebreus aceitavam-na; os Judeus nos dias de Cristo a realizaram; O cristianismo sempre acreditou nisso; e para o homem primitivo também a imortalidade era uma certeza, não uma conjectura. Sobrevivência após a morte foi como o homem interpretou a intuição inextirpável enraizada no núcleo imperecível de seu ser.

No entanto, enfrentamos a possibilidade de acabar com nossas vidas através da morte antes de causas naturais, por exemplo. Aqui é quando o suicídio entra na discussão. Afinal, "[...] a possibilidade do suicídio se abre apenas pelo fato de podermos controlar quanto tempo vivemos. Mas esta é, de fato, uma das poucas coisas sobre a morte que podemos realmente controlar: se eu escolher, posso terminar minha vida antes do que terminaria." (KAGAN, 2012, p. 318, tradução nossa, grifo do autor). Com isso, a " morte é um evento inevitável: sua ocorrência não está em nossas mãos, mas seu tempo pode estar, se assim escolhermos." (SZASZ, 2011, p.2, tradução nossa).

De acordo com Durkheim (2002, n.p., grifo do autor, tradução nossa), “[...] o termo suicídio é aplicado a todos os casos de morte resultando diretamente ou indiretamente de um ato positivo ou negativo da própria vítima, que ela sabe que produzirá esse resultado."

Na Bíblia, embora muitas religiões desaprovem o ato de cometer suicídio, não há uma proibição explícita sobre o suicídio. O que se observa é uma ambivalência através dos textos sagrados entre reprovação e enaltecimento. A título de ilustração poderíamos citar a morte de Sansão (Juízes, 16:28), onde se relata ato de heroísmo, e de Judas (Mateus, 27:3-5) num ato de arrependimento pela traição a Jesus (KING JAMES BIBLE, n.d.). 
O suicídio no mundo antigo não teve as mesmas conotações negativas que observamos na sociedade contemporânea. Para os filósofos greco-romanos, o suicídio em algumas circunstâncias constituía numa morte nobre. No julgamento de Sócrates, por exemplo, ele optou por beber a cicuta e, consequentemente, a morte, do que fugir e viver uma vida que, para ele, não mais valeria a pena ser vivida (PLATÃO, n.d.).

Do mesmo modo, ao longo da história do Japão, o chamado seppuku ou hara-kiri, era uma prática conhecida entre os samurais japoneses. Um tipo de suicídio praticado por uma perspectiva de bravura e heroísmo. No sentido literal, os termos são traduzidos por cortar o ventre, porém, em um sentido contextual, os guerreiros japoneses tiravam a vida pela própria pátria, ato de honra ou amor (DIAS, 2018).

Segundo Ariès (1977), o evento do morrer é considerado um assunto privado, fazendo parte da esfera íntima. No entanto, quando o suicídio ocorre, ele contradiz o modo ocidental de morte e vai para a esfera pública. Além disso, ao longo da história ocidental, o suicídio sempre foi influenciado pelo contexto cultural de cada época.

No decorrer da história da humanidade, o suicídio foi considerado pecado e, até mesmo, criminalizado (DURKHEIM, 2002). Na sociedade contemporânea, existem ainda poucos países que consideram este fenômeno como um crime. Contudo, para a maioria dos países o suicídio não é codificado nas legislações como um crime. Deste modo, "como um fenômeno, o suicídio é antigo. Como um problema médico, ele é recente.” (SZASZ, 2011, p. 9, tradução nossa).

Na legislação brasileira o suicídio não é considerado crime. A lei não pune aquele que por ato próprio comete suicídio, logicamente porque não há como punir aquele que já está morto, ou seja, já não existe no mundo dos vivos. Não há, portanto, como punir um cadáver. Também inexiste punição para a tentativa.

Entrementes, quando falamos em suicídio, no atual Código Penal Brasileiro só se manifesta no que diz respeito a indução ou instigação e, prestação de auxílio para que alguém se suicide. Assim, extraímos o seguinte do disposto do Art. 122, Código Penal: "Induzir ou instigar alguém a suicidar-se ou prestar-lhe auxílio para que o faça: Pena - reclusão, de dois a seis anos, se o suicídio se consuma; ou reclusão, de um a três anos, se da tentativa de suicídio resulta lesão corporal de natureza grave.” (BRASIL, 1940).

Neste contexto, importante identificar os significados de induzir, instigar e auxiliar. De acordo com a doutrina, para Guilherme de Souza Nucci (2014), induzir significa dar ou 
criar uma ideia a quem não a possuir, ou seja, inspirar ou incutir em alguém uma ideia. Instigar significa dar força, fomentar ou estimular uma ideia que já existente. E, por fim, auxiliar significa fornecer o suporte material para que o agente concretize o ato suicida.

Atualmente, a título de curiosidade, existem correntes que pregam pelo suicídio como um direito, ou seja, o direito à morte, como uma faculdade da liberdade que o cidadão goza em um estado democrático de Direito (SZASZ, 1999).

Para o psiquiatra Thomas Szasz (1973, p.67, grifo nosso, tradução nossa), o "suicídio é um direito humano fundamental. Isso não significa que é moralmente desejável. Isso só significa que a sociedade não tem o direito moral de interferir, por força, com a decisão do indivíduo em cometer esse ato".

Outros, no entanto, defendem o direito à morte só em circunstâncias em que a continuação da existência se torna algo insuportável, inviável e, portanto, indigno, isto é, afetaria negativamente a dignidade da pessoa humana e, neste caso, a eutanásia e o suicídio assistido seriam admissíveis (GOUVÊA; DEVAL, 2018).

Enfim, a discussão em torno do tema é bastante complexa e desafiadora, uma vez que envolve correntes distintas. E, nesse sentido, a contemporaneidade de nossa sociedade propicia uma discussão ainda mais abrangente, vez que que coaduna teóricos clássicos e modernos, demonstrando que o tema não é uma preocupação somente de hoje, mas vem de um passado, perpassando pelo presente e, quiçá, se estenderá pelo futuro.

\section{O suicídio na sociedade contemporânea: certezas e incertezas}

Quando a vida está num estágio muito ruim, isto é, onde o indivíduo se depara com constantes frustrações, quando a melancolia se torna o martelo que espatifa continuamente nossas esperanças, então, começamos a cogitar a abreviação deliberada de nossas existências. Essa cogitação - ou mesmo o ato de se matar - parece ser uma decisão pessoal, ou seja, que parte do nosso íntimo, um ato aparentemente tão privado, dependente de fatores pessoais, um ato do indivíduo que afeta somente a ele, um fenômeno, outrossim, que se situaria exclusivamente no campo da psicologia.

Contudo, não é bem assim. Émile Durkheim, insigne sociólogo francês, irá propor, em sua famosa obra $O$ Suicídio, que existem fatores sociais que são protetivos da vida, em outas palavras, o suicídio como um fato social. Para Durkheim (2002), a opção pela 
abreviação deliberada da existência é justificada pela fragilização dos laços sociais do entristecido. Corroborando a reflexão, Clóvis de Barros Filho e Arthur Meucci (2012, n.p.) afirmam que, "[...] a importância que temos na vida dos outros e a importância que os outros têm na nossa vida acabam se constituindo em fatores que a protegem de nós mesmos em momentos de tristeza". No mesmo sentido, Primo Levi (p.15, 1988), na obra É isto um homem?, dirá que:

\begin{abstract}
Cedo ou tarde, na vida, cada um de nós se dá conta de que a felicidade completa é irrealizável; poucos, porém, atentam para a reflexão oposta: que também é irrealizável a infelicidade completa. Os motivos que se opõem à realização de ambos os estados-limite são da mesma natureza; eles vêm de nossa condição humana, que é contra qualquer "infinito". Assim, opõe-se a esta realização o insuficiente conhecimento do futuro, chamado de esperança no primeiro caso e de dúvida quanto ao amanhã, no segundo. Assim, opõe-se a ela a certeza da morte, que fixa um limite a cada alegria, mas também a cada tristeza. Assim, opõem-se as inevitáveis lides materiais que, da mesma forma como desgastam com o tempo toda a felicidade, desviam a cada instante a nossa atenção da desgraça que pesa sobre nós tornando a sua percepção fragmentária, e, portanto, suportável.
\end{abstract}

Nossa sociedade contemporânea, ou conforme prefere denominar Byung-Chul Han (2015), achievement society - sociedade da realização -, é uma sociedade caracterizada e constantemente e bombardeada pelo excesso de positividade. Slogans do tipo No Pain, No Gain!, ou então, Just do it!, são exemplos comuns e notórios desta overdose de positividade que marca nossa sociedade contemporânea. Acabamos nos tornando deuses de nós mesmos, ou escravos de um sistema que nos força a pensar de uma forma extremamente individualista. E, quando não conseguimos alcançar determinados padrões, nos frustramos, entramos em um estado de esgotamento.

A sociedade da realização produz, por outro lado, o excesso de cansaço e exaustão. Em outras palavras, “[...] a excessividade de melhoria de performance leva a infartos psíquicos. " (HAN, 2015, p. 31, tradução nossa).

De acordo com Byung-Chul Han (2015, p. 1, tradução nossa, grifo do autor), vivemos em uma era marcada não mais por doenças epidêmicas, como vírus ou bactérias, mas sim,

[...] doenças neurológicas, como depressão, transtorno do déficit de atenção e hiperatividade (TDAH), transtornos de personalidade da fronteira (DBP) e síndrome de burnout marcam a paisagem da patologia no início do século XXI. Eles não são infecções, mas infarto; eles não derivam da negatividade do que é imunologicamente estranho, mas de um excesso de positividade. Portanto, eludem todas as tecnologias e técnicas que buscam combater o que é alienígena. 
Dentro das próprias relações, estamos sempre virtualmente conectados com todos e todo o mundo, mas no final das contas, estamos sempre sozinhos. Com a entrada de tecnologias de comunicação percebemos grande fragilização nos laços sociais - ou um ilusório fortalecimento nos laços sociais. Sobre esse fenômeno nas relações sociais, Bauman (2004, n.p.) dirá que:

\begin{abstract}
Elas são "relações virtuais". Ao contrário dos relacionamentos antiquados (para não falar daqueles com "compromisso" muito menos dos compromissos de longo prazo), elas parecem feitas sob medida para o líquido cenário da vida moderna, em que se espera e se deseja que as "possibilidades românticas" (e não apenas românticas) surjam e desapareçam numa velocidade crescente e em volume cada vez maior, aniquilando-se mutuamente e tentando impor aos gritos a promessa de "ser a mais satisfatória e a mais completa". Diferentemente dos "relacionamentos reais" é fácil entrar e sair dos "relacionamentos virtuais". Em comparação com a "coisa autêntica", pesada, lenta e confusa, eles parecem inteligentes e limpos, fáceis de usar, compreender e manusear. Entrevistado a respeito da crescente popularidade do namoro pela Internet, em detrimento dos bares para solteiros e das seções especializadas dos jornais e revistas, um jovem de 28 anos da Universidade de Bath apontou uma vantagem decisiva da relação eletrônica: "Sempre se pode apertar a tecla de deletar".
\end{abstract}

Portanto, na sociedade contemporânea, o excesso de positividade e a falsa aparência de vivermos rodeados por amigos virtuais são fatores sociais gerais que levam as pessoas ao entristecimento, devido a uma sensação de isolamento muito particular o que, por fim, leva ao suicídio.

Ademais, importante enfatizar que vivemos em uma sociedade capitalista, marcada por desigualdades sociais, exploração ao extremo, opressão, individualismo, competitividade, desemprego, corrupção, crises econômicas etc. Todos esses são elementos que influenciam na ideação, tentativa e consumação dos suicídios (CONSELHO FEDERAL DE PSICOLOGIA, 2013).

Há, portanto, uma gama muito grande a respeito das causas do suicídio, todavia, poderíamos afirmar que as maiores causas de suicídio estão relacionadas a depressão, doenças mentais, uso de substâncias entorpecentes e alcoolismo, excesso de trabalho e/ou atividades do dia a dia, desemprego, bullying, violência sexual, aspectos sociais, culturais e políticos. Ressalta-se que, o suicídio não é considerado como uma decisão concreta do indivíduo, mas fruto de uma doença social. Assim, isto faz com que o suicídio seja um dos problemas eternos da humanidade, caracterizado por uma multidimensionalidade e uma interação complexa de causas externas e internas deste comportamento, merecendo destacado lugar nos espaços de 
debates acerca da efetivação do direito humano fundamental à saúde, bem como suas políticas públicas de promoção, que visam prevenir o suicídio e promover a vida.

\section{Para além da concepção de suicídio: o conceito de saúde enquanto direito humano fundamental e as políticas públicas}

Imaginemos, a título de ilustração, uma pessoa que viveu até os 100 anos de idade, porém, cada momento de sua vida foi marcado por dores e sofrimentos. Imaginemos também, uma pessoa que viveu até os 50 anos de idade, porém, sem tantas dores e sofrimentos, mas com mais saúde e gozos. Percebemos nos dois casos, uma diferença abrupta, pois o fato de viver mais não significa viver melhor, ou seja, o que logicamente importa não é quantidade de anos vividos, mas sim, a qualidade desses anos vividos.

Isso porque, "[...] uma coisa é gozar alegremente a vida quando o nível de energia é alto e todas as faculdades estão totalmente intactas. Outra coisa é curtir a vida mesmo quando está com dor extrema, incapaz de fazer qualquer coisa física e mental ou mentalmente deteriorada" (HOSPICE PATIENTS ALLIANCE, n.d., n.p., tradução nossa).

Comumente, equivocamo-nos ao interpretar a saúde como a simples ausência de doenças. De acordo com a Constituição da Organização Mundial da Saúde (1946, p.1, tradução nossa), a definição de saúde se dá da seguinte maneira: "A saúde é um estado de completo bem-estar físico, mental e social e não apenas a ausência de doença ou enfermidade". Podemos perceber, portanto, que o conceito de saúde vai muito além de uma consulta médica, ou fornecimento de medicamentos e tratamentos garantidos pelo Estado. Esse conceito, por ter uma amplitude maior, perpassa outras esferas como a qualidade de vida do indivíduo, a alimentação, a moradia, o trabalho, o ambiente em que vive etc.

Para Donald Chittick (1998), a preocupação e busca pela saúde aparece no decorrer da história, onde as primeiras civilizações já demonstravam conhecimento científico e tecnologias para a busca e manutenção da saúde.

No mesmo contexto, Schwartz (2001) afirma que o primeiro entendimento de saúde nasceu com os gregos na premissa Mens Sana In Corpore Sano, que se traduz por uma mente sã num corpo são, isto é, um equilíbrio harmônico entre o corpo e a mente.

Foi com a introdução do Welfare State - Estado de Bem-Estar Social - que o Estado passou a assumir a função de garantidor da saúde pública (FIGUEIREDO, 2007). Interessante 
ressaltar que o conceito de saúde evoluiu de uma concepção curativa, ou seja, a simples cura de doenças, ou mesmo, preventiva, de prevenir o adoecimento das pessoas, para uma perspectiva mais ampla. Todavia, tais hipóteses ostentam um caráter organicista na medida em que compreendem a saúde como a mera ausência de doenças e não avaliam outros elementos como o aspecto social, por exemplo (BARRIQUELLO; STURZA, 2018).

Diante disso, o direito à saúde surge como uma garantia ao cidadão fornecida pelo Estado com o objetivo não só curar doenças, mas também, prover meios para preveni-las, ou seja, o direito à saúde não se dá somente aquelas pessoas que estão adoentadas, mas como um direito de todos, doentes e saudáveis.

Na Declaração Universal dos Direitos Humanos de 1948, art. 25, item 1, temos o seguinte:

1.Toda a pessoa tem direito a um nível de vida suficiente para lhe assegurar e à sua
família a saúde e o bem-estar, principalmente quanto à alimentação, ao vestuário, ao
alojamento, à assistência médica e ainda quanto aos serviços sociais necessários, e
tem direito à segurança no desemprego, na doença, na invalidez, na viuvez, na
velhice ou noutros casos de perda de meios de subsistência por circunstâncias
independentes da sua vontade.

No Brasil, na Constituição Federal de 1988, o direito à saúde é uma garantia fundamental social disposta no art. $6^{\circ}$, e arts. 196 a 200. Destacamos aqui o art. 196, onde está expresso que: "A saúde é direito de todos e dever do Estado, garantido mediante políticas sociais e econômicas que visem à redução do risco de doença e de outros agravos e ao acesso universal e igualitário às ações e serviços para sua promoção, proteção e recuperação”. Neste sentido,

[...] a saúde, aqui, é vista e estudada enquanto "qualidade de vida", garantida principalmente através da promoção e prevenção de doenças, sendo, a cura, utilizada para os casos em que as duas anteriores não foram suficientes para garantir a plena qualidade de vida ao cidadão. Todas essas dimensões são garantidas por um sistema que age em prol da sociedade e do cidadão. (BARRIQUELLO, STURZA, 2018, p.87).

Tem-se, assim, que a introdução dos conceitos de promoção da saúde e prevenção de doenças são, até o presente momento, as melhores alternativas para lidar com os problemas de saúde pública e, consequentemente, contribuem para uma melhor qualidade de vida. Diante desta perspectiva de promoção e prevenção, o direito à saúde dar-se-á de forma coletiva, isto porque tem o objetivo de promover a inclusão social e permitir maior participação e envolvimento político dos cidadãos nas decisões do Estado. 
Neste contexto, importante destacar a elaboração e implementação de políticas públicas de saúde para que os cidadãos possam ter acesso mais amplo aos programas e serviços de saúde. Entende-se que uma das funções de um Estado Democrático é zelar pelo bem-estar da sociedade. Para que isso seja possível, o Estado tem de atuar e desenvolver ações sobre áreas primordiais tais como saúde, educação, meio ambiente, entre outras. As políticas públicas são uma das principais formas para que se possa atuar nessas áreas. Assim, “[...] políticas Públicas são um conjunto de ações e decisões do governo, voltadas para a solução (ou não) de problemas da sociedade.” (SEBRAE MG, 2008, p. 5). Já, para Vallès (2002, p. 37), as políticas públicas são

[...] un conjunto interrelacionado de decisiones y no decisiones, que tienen como foco un área determinada de conflicto o tensión social. Se trata de decisiones adoptadas formalmente en el marco de las instituciones públicas - lo cual les confiere la capacidad de obligar -, pero que han sido percebidas de un processo de elaboración en el cual han participado una pluraridad de actores públicos y privados.

Deste modo, o Estado passou a ser alcunhado de Estado Previdência, cabendo-lhe a execução de políticas públicas que dessem conta das mais variadas necessidades de uma sociedade cada vez mais complexa. Todavia, os esforços para a prevenção do suicídio devem ser direcionados através de uma análise multidisciplinar, isto é, deve-se sempre levar em consideração os contextos sociais onde estão inseridas aquelas pessoas que estão mais sujeitas e/ou propensas à contemplação suicida. No entanto, a aplicabilidade deste paradigma holístico se torna proporcionalmente mais dificultosa quando colocada no contexto de países cujas extensões territoriais juntamente com as diversidades culturais que apresentam tornam o fenômeno do suicídio ainda mais complexo de ser compreendido, mormente, prevenido (KOCH; OLIVEIRA, 2015).

No caso da saúde, de acordo com Lucion e Sturza (2018, p. 29), "as políticas públicas de promoção da saúde, as quais, por meio da ações que favorecem o bem estar das pessoas e manutenção da saúde, acabam também por promover o direito à saúde.”

No contexto do suicídio, de acordo com levantamento feito pela Organização Mundial da Saúde (2018) - World Health Organization - cerca de 800.000 pessoas morrem por suicídio a cada ano. Isso, através de cálculos matemáticos, representaria a morte de uma pessoa a cada 40 segundos. Neste seguimento, o suicídio é globalmente considerado a segunda maior causa de morte em pessoas com faixa etária de 15 a 29 anos. Ainda assim, para cada 1 suicídio executado, 20 outros são tentados. 
No Brasil, cerca de 106.374 mortes por suicídio foram registradas do ano de 2007 a 2016. Representa uma média de 11 mil mortes a cada ano no Brasil, e é a quarta maior causa de mortes entre jovens, a partir dos 15 anos de idade aos 29 anos de idade (MINISTÉRIO DA SAÚDE, 2018).

Todos estes números são responsáveis por nos levar a uma única conclusão: o suicídio tornou-se um problema de saúde pública. Esses dados são alarmantes e preocupantes e nos revelam a necessidade de buscar alternativas na tentativa de reduzir esses números de mortes por suicídios. Precisamos de políticas públicas de prevenção ao suicídio no Brasil.

Algumas atitudes já vêm sendo tomadas com a finalidade de prevenção. É o caso da instituição do dia 10 de Setembro como o Dia Mundial de Prevenção ao Suicídio. No Brasil, esta data ficou conhecida como o Setembro Amarelo, isto é, uma campanha de prevenção e conscientização onde prédios e monumentos históricos são iluminados e/ou decorados com a cor amarela (FIOCRUZ, 2016).

Além disso, no Brasil, temos os chamados Centros de Atenção Psicosocial - CAPS -, que são:

[...] serviços de saúde de caráter aberto e comunitário constituído por equipe multiprofissional e que atua sobre a ótica interdisciplinar e realiza prioritariamente atendimento às pessoas com sofrimento ou transtorno mental, incluindo aquelas com necessidades decorrentes do uso de álcool e outras drogas, em sua área territorial, seja em situações de crise ou nos processos de reabilitação psicossocial e são substitutivos ao modelo asilar. (MINISTÉRIO DA SAÚDE, 2017, n.p.).

Os CAPS, portanto, tem fundamental relevância devido ao papel que desempenham, mesmo que indiretamente, em termos de prevenção ao suicídio. Os CAPS vieram em substituição aos antigos manicômios e possuem um perfil diferenciado em relação aos antigos métodos e tratamentos psiquiátricos, porque conta com equipes multidisciplinares de profissionais da saúde e tem um caráter acolhedor e objetiva a inserção social do indivíduo.

Ademais, no Rio Grande do Sul, já existem discussões para a implantação de um projeto piloto, através da criação de um observatório na tentativa de coletar dados e identificar possíveis grupos de risco. Por ser considerado o Estado brasileiro com maior índice de suicídios, o projeto demonstra ser algo pioneiro em termos de prevenção no contexto nacional. A ideia é fazer levantamento de dados para análises demográficas, sociais e epidemiológicas, com o objetivo de subsidiar políticas públicas de prevenção ao suicídio dentro do Estado (DI LORENZO, 2017). 


\section{CONSIDERAÇÕES FINAIS}

O suicídio - a partir do binômio vida e morte, é um fenômeno caracterizado por uma gama muito ampla de fatores e causas, e sua prevenção, do mesmo modo, há que ser proposta de uma forma multifatorial e multicausal. Podemos, assim, prevenir os suicídios através de políticas centralizadas na saúde pública, no biodireito e nos direitos humanos, que se voltem a promover cidadania e não intolerância, que busquem erradicar as desigualdades sociais, o reconhecimento das minorias. Nas escolas, trabalhar igualmente, a valorização da vida. $\mathrm{Na}$ mídia, campanhas de esclarecimento. Na saúde, maior capacitação, treinamento e preparo para os profissionais da saúde com a finalidade de lidarem melhor com pessoas que tem pensamentos suicidas. Na legislação, restringir o acesso a meios letais, como armas e fármacos, pelo menos temporariamente, durante um período de crise pode impedir o suicídio.

Ainda, importante destacar que não podemos rotular o indivíduo suicida como um mero louco, com distúrbio psíquico ou biológico que deve ser tratado a base de fármacos químicos, mas buscar discutir abertamente o fenômeno do suicídio e desmistificar e/ou desconstruir os tabus e mitos sobre o tema, ou seja, desenvolver e reforçar estratégias de prevenção com abordagem multisetorial, de forma a quebrar estigmas e tabus que existem sobre este tema.

Como fora observado, nossa sociedade contemporânea carece em laços sociais. Políticas públicas de prevenção ao suicídio são uma tentativa de fortalecer esses laços sociais, especialmente, dos grupos mais vulneráveis, identificando as principais causas e fornecendo todo o tipo de auxílio necessário, pois a saúde é um direito humano fundamental, do qual resulta o nosso bem maior - a vida.

A saúde é um direito e dever do Estado. Todavia, a saúde não deve ser confundida simplesmente com a ausência de doenças, mas sim, deve ser compreendida como o bem-estar físico, mental e social. Portanto, seguindo este ideário, devemos prevenir o suicídio não somente através da perspectiva física e mental com a medicalização e hospitalização do indivíduo suicida, mas também na perspectiva sociojuridica, através da educação e da formulação e implementação de políticas públicas, capazes de fomentar e indicar determinantes sociais e marcos regulatórios sanitários, que de fato - e não somente de direito, garantam o direito humano fundamental à saúde, protegendo a vida e a própria espécie humana. 


\section{REFERÊNCIAS}

ARIÈS, Phillipe. História da Morte no Ocidente: da Idade Média aos nossos dias. Rio de Janeiro, F. Alves, 1977.

BARRIQUELLO, Carolina Andrade; STURZA, Janaína Machado. As conformações contemporâneas para a garantia do acesso ao direito fundamental à saúde: dimensões preventiva e promocional. Cadernos Ibero-Americanos de Direito Sanitário, 2018. Disponível em: <https://www.cadernos.prodisa.fiocruz.br/index.php/cadernos/article/view/431/518>.

Acesso em: 22 mar. 2019.

BARROS FILHO, Clóvis de.; MEUCCI, Arthur. A vida que vale a pena ser vivida. Petrópolis, Rio de Janeiro: Vozes, 2012.

BAUMAN, Zygmunt. Amor líquido: sobre a fragilidade dos laços humanos. Trad.: Carlos Alberto Medeiros. Rio de Janeiro: Jorge Zahar, 2004. Disponível em:< http://static.tumblr.com/jh0avtj/8xdooienw/amor_liquido_-_zygmunt_bauman.pdf>. Acesso em: 20 mar. 2019.

BRASIL. Constituição (1988). Constituição da República Federativa do Brasil de 1998. Disponível em:<http://www.planalto.gov.br/ccivil_03/Constituicao/Constituicao.htm>. Acesso em: 28 mar. 2019.

BRASIL. Decreto-lei no 2.848, de 7 de dezembro de 1940. Código Penal. Disponível em:< http://www.planalto.gov.br/ccivil_03/decreto-lei/Del2848compilado.htm>. Acesso em: 28 mar. 2019.

CARNELL, Edward John. An Introduction to Christian Apologetics: A Philosophic Defense of the Trinitarian-Theistic Faith. Eugene, Oregon: Wipf and Stock Publishers, 2007.

CHITTICK, Donald. The puzzle of ancient man: advanced technology in past civilizations? Newberg, Oregon: Creation Compass, 1998.

CONSELHO FEDERAL DE PSICOLOGIA. O suicídio e os desafios para a psicologia. Brasília: CFP, 2013. Disponível em:<https://site.cfp.org.br/wpcontent/uploads/2013/12/Suicidio-FINAL-revisao61.pdf>. Acesso em: 28 mar. 2019.

CONSTITUTION OF THE WORLD HEALTH ORGANIZATION. 1946. Disponível em:< https://www.who.int/governance/eb/who_constitution_en.pdf>. Acesso em: 10 mar. 2018.

CRAIG, William Lane. The kalam cosmological argument. Oregon: Wipf and Stock Publishers, 1979.

DARWIN, Charles. A origem das espécies. Trad.: Joaquim Dá Mesquita Paul. São Paulo: Martin Claret, 2014. 
DECLARAÇÃO UNIVERSAL DOS DIREITOS HUMANOS DE 1948. Disponível em:< https://www.ohchr.org/EN/UDHR/Documents/UDHR_Translations/por.pdf>. Acesso em: 22 mar. 2019.

DIAS, Bruno. Tudo sobre o seppuku, o ritual de suicídio japonês. 2018. Disponível em:< https://www.fatosdesconhecidos.com.br/tudo-sobre-o-seppuku-o-ritual-de-suicidio-japones/>. Acesso em: 24 mar. 2019.

DI LORENZO, Alessandro. Projeto prevê ações de prevenção ao suicídio no RS: objetivo é reunir informações para criação de políticas públicas ligadas ao tema. 2017. Disponível em:<https://bandrs.band.com.br/noticias/100000865824/projeto-preve-acoes-de-prevencaoao-suicidio-no-rio-grande-do-sul.html>. Acesso em: 28 mar. 2019.

DURKHEIM, Émile. Suicide. New York: Routledge, 2002.

FIGUEIREDO, Mariana Filchtiner. Direito fundamental à saúde: parâmetros para sua eficácia e efetividade. Porto Alegre: Livraria do Advogado, 2007.

FIOCRUZ. Suicídio. 2016. Disponível em:<https://agencia.fiocruz.br/suicidio >. Acesso em: 28 mar. 2019.

GOUVÊA, Gisele Gomes; DEVAL, Rafael Antônio. O direito de morrer e a dignidade da pessoa humana. Revista CEJ, Brasília, Ano XXII, n. 75, p. 51-58, maio/ago. 2018. Disponível em:< file://C:/Users/USER/Downloads/Artigo\%2011\%20\%20indicado\%20(3).pdf>. Acesso em: 19 fev. 2019.

HAN, Byung-Chul. The burnout society. Stanford, California: Stanford University Press, 2015.

HOSPICE PATIENTS ALLIANCE. Quality of life and quantity of life: not the same. Disponível em:< https://hospicepatients.org/hospic32.html>. Acesso em: 20 mar. 2019.

KAGAN, Shelly. Death. New Haven and London: Yale University Press, 2012.

KING JAMES BIBLE. Holy bible. Disponível em:< https://www.kingjamesbibleonline.org/>. Acesso em: 26 mar. 2019.

KOCH, Daniel Buhatem; OLIVEIRA, Paulo Rogério Melo de. As políticas públicas para a prevenção de suicídios. Revista Brasileira de Tecnologias Sociais, v.2, n.2, 2015. UNIVALI, Universidade do Vale do Itajaí. Disponível em:< file:///C:/Users/User/Downloads/922625358-1-SM.pdf>. Acesso em: 22 dez. 2018.

KÜBLER-ROSS, Elisabeth. Death: the final stage of growth. New York: Touchstone, 1986.

LANZA, Robert. BERMAN, Bob. Biocentrism: how life and consciousness are the keys to understanding the true nature of the universe. Dallas: Benbella Books, 2010. 
LEVI, Primo. É isto um homem? Trad.: Luigi Del Re. Rio de Janeiro: Editora Rocco LTDA, 1988.

LUCION, Maria Cristina Schneider; STURZA, Janaína Machado. A arqueologia do reconhecimento da saúde como direito: o surgimento de um elemento de cidadania. In: STURZA, Janaína Machado; AQUINO, Quelen Brondani de. Direitos humanos e cidadania. Porto Alegre: Editora Evangraf Ltda., 2018.

MINISTÉRIO DA SAÚDE. Centro de atenção psicossocial (CAPS). 2017. Disponível em:<http://portalms.saude.gov.br/noticias/693-acoes-e-programas/41146-centro-de-atencaopsicossocial-caps>. Acesso em: 28 mar. 2019.

MINISTÉRIO DA SAÚDE. Novos dados reforçam a importância da prevenção do suicídio. 2018. Disponível em:< http://portalms.saude.gov.br/noticias/agencia-saude/44404novos-dados-reforcam-a-importancia-da-prevencao-do-suicidio>. Acesso em: 17 fev. 2019.

NUCCI, Guilherme de Souza. Manual de Direito Penal. $10^{\circ}$ ed. Rio de Janeiro: Editora Forense, 2014.

Disponível em: <https://direitouniversitarioblog.files.wordpress.com/2017/02/manual-do-direito-penalguilherme-nucci.pdf> Acesso em: 28 mar. 2019.

PLATÃO. A apologia de Sócrates. Disponível em:< http://www.revistaliteraria.com.br/plataoapologia.pdf>. Acesso em: 25 mar. 2019.

SCHWARTZ, Germano. Direito à saúde: efetivação em uma perspectiva sistêmica. Porto Alegre: Livraria do Advogado, 2001.

SEBRAE MG. Políticas públicas: conceitos e práticas. Vol. 7. 2008. Disponível em:< http://www.mp.ce.gov.br/nespeciais/promulher/manuais/MANUAL\%20DE\%20POLITICAS \%20P\%C3\%9ABLICAS.pdf>. Acesso em: 25 mar. 2019.

SZASZ, Thomas. Fatal freedom. London: Praeger, 1999.

SZASZ, Thomas. Suicide prohibition: the shame of medicine. New York: Syracuse University Press, 2011.

SZASZ, Thomas. The second sin. Garden City, New York: Anchor Press Doubleday \& Company, Inc., $1973 . \quad$ Disponível em:< https://equalityfiles.files.wordpress.com/2013/12/thomas_szasz_the_second_sin.pdf >. Acesso em: 21 mar. 2019.

THOMAS, J.G.S.S. Death and the state of the soul after death. In: Contemporary Evangelical Thought: Basic Christian Doctrines. Dallas, Texas: Digital publications the electronic bible $\quad$ society, 2002. $\quad$ Disponível em:< http://www.veritasseminary.com/wenix/Library/Carl\%20Henry/CARL\%20F\%20H\%20HEN RY\%20CONTEMPORARY\%20EVANGELICAL\%20THOUGHT\%20VOL\%2003\%20BAS IC\%20CHRISTIAN\%20DOCTRINES.pdf>. Acesso em: 27, fev. 2019. 
VALLÈS, Josep M. Las políticas públicas. Barcelona: Ariel, 2002.

WORLD HEALTH ORGANIZATION. Latest data on suicide. 2018. Disponível em:< http://www.who.int/mental_health/suicide-prevention/en/>. Acesso em: 01 dez. 2018. 